\title{
Pengembangan Ensiklopedia Tata Surya Berbasis Pendekatan Inkuiri untuk Siswa Kelas III Sekolah Dasar
}

\author{
${ }^{1}$ Arnelia Dwi Yasa, ${ }^{2}$ Cicilia Ika Rahayu Nita, ${ }^{3}$ Adelya Mega Insan Putri \\ ${ }^{1,2,3}$ Prodi PGSD, FKIP Universitas Kanjuruhan Malang, Indonesia \\ arnelia@unikama.ac.id
}

\begin{abstract}
Abstrak
Gerakan literasi dilakukan dengan cara membaca buku selain mata pelajaran dalam waktu lima belas menit sebelum melaksanakan kegiatan pembelajaran. Tujuan penelitian ini adalah mengembangkan ensiklopedia tata surya yang valid, praktis, dan efektif. Penelitian ini adalah penelitian $R \& D$ (Research and Development) dengan metode penelitian ADDIE dengan empat tahapan yaitu analisis, desain, pengembangan, dan implementasi.

Dalam metode ini tahapan evaluasi tidak dilakukan atas dasar keterbatasan waktu penelitian. Langkah yang terdapat dalam penelitian berikut berupa analisis kebutuhan, proses kerangka desain, pengembangan instrumen validasi oleh ahli media, ahli materi, dan ahli bahasa, serta implementasi ensiklopedia kepada 10 orang siswa dalam uji lapangan serta guru wali kelas III SDN Sukun 1 Malang. Hasil penelitian diperoleh rata-rata validasi oleh ahli media sebesar 92\% layak digunakan, dari ahli materi sebesar 96\% layak digunakan, dan dari ahli bahasa sebesar 93\% layak digunakan. Sedangkan, kepraktisan ensiklopedia tata surya dari guru sebesar $80 \%$ dan siswa kelas III sebesar $87 \%$. Uji keefektifan sebesar $81 \%$ yang menunjukkan bahwa modul efektif untuk digunakan.
\end{abstract}

Kata kunci: Ensiklopedia; SD; Tata surya 


\section{PENDAHULUAN}

Kurikulum 2013 berorientasi pada peningkatan dan keseimbangan antara kompetensi sikap (attitude), keterampilan (skill), dan pengetahuan (knowledge). Kurikulum 2013 dapat dijadikan sebagai sebuah fasilitas oleh guru dalam melaksanakan pembelajaran yang mendorong kemampuan berfikir kritis siswa. ${ }^{1}$ Aktivitas yang dilakukan sebagai upaya untuk menunjang keberhasilan pelaksanaan kurikulum 2013 adalah melalui sebuah gerakan pemerintah yang dinakaman gerakan literasi sekolah. Gerakan literasi sekolah memiliki manfaat dalam meningkatkan minat baca siswa dan meningkatkan keterampilan membaca supaya peserta didik menguasai pengetahuan dengan baik.

Gerakan ini mewajibkan siswa membaca selama 15 menit di awal pembelajaran untuk dijadikan kebiasaan yang membudaya. ${ }^{2}$ Penelitian sebelumnya dengan judul Implementasi Gerakan Literasi Sekolah Pada Pembelajaran Tematik Di Sekolah Dasar menyatakan bahwa literasi efektif dan dinilai produktif untuk menjadikan siswa terampil dalam mencari informasi serta mengolahnya untuk memperkaya ilmu pengetahuan dalam abad $21 .^{3}$

Berdasarkan hal tersebut guru harus memiliki inovasi untuk membuat bahan bacaan yang menarik bagi siswa agar dapat meningkatkan minat baca siswa dalam menggali ilmu pengetahuan sehingga gerakan literasi di sekolah berjalan dengan baik. Hal tersebut sesuai dengan penelitian terkait inovasi pembelajaran dan integrasi pendidikan karakter untuk meningkatkan hasil belajar siswa, dimana mutu pendidikan serta perbaikan sumber daya manusia dapat mewujudkan daya saing bangsa melalui pengadaan buku ajar yang bermutu. ${ }^{4}$

\footnotetext{
${ }^{1}$ Azizah, M., Sulianto, J., \& Cintang, N. (2018). Analisis Keterampilan Berpikir Kritis Siswa Sekolah Dasar pada Pembelajaran Matematika Kurikulum 2013. Jurnal Penelitian Pendidikan A \& A, 35(1), 61- 70.

${ }^{2}$ Rohman Sayifur. (2017). Membangun Budaya Membaca Pada Anak Melalui Program Gerakan Literasi Sekolah. Jurnal Pendidikan Dan Pembelajaran Dasar, 4, $\quad$ 151174.

${ }^{3}$ Suyono, Harsiati, T., \& Wulandari, I. S. (2017). Implementasi gerakan literasi sekolah pada pembelajaran tematik di sekolah dasar. Sekolah Dasar: Kajian Teori Dan Praktik Pendidikan, 116-123.

${ }^{4}$ Situmorang, M. (2013). Pengembangan Buku Ajar Kimia SMA melalui Inovasi Pembelajaran dan Integrasi Pendidikan Karakter untuk Meningkatkan Hasil Belajar Siswa. Semirata FMIPA Universitas Lampung, 1(1), 237-246.
} 
Melalui hasil observasi pada tanggal 23 Oktober 2019 di perpustakaan SDN Sukun 1 Malang, menunjukan masih banyak buku tata surya yang kurang menarik dan tidak memiliki kualitas gambar yang baik. Seperti warna gambar planet yang buram, ukuran gambar planet yang terlalu kecil sehingga tidak bisa diamati dengan jelas, bahan buku yang mudah sobek, serta terlalu banyak teks membuat siswa bosan untuk membaca.Hal tersebut tentu dapat mengurangi minat siswa dalam membaca, terutama dalam materi tata surya.

Ensiklopedia merupakan bahan ajar yang dibuat berupa buku dengan desain yang menarik. Ensiklopedia adalah sebuah buku yang berisi keterangan seperti definisi, latar belakang, serta data bibliografis yang disusun sistematis dan berdasarkan alfabetis. ${ }^{5}$ Aspek yang diutamakan dalam ensiklopedia berupa desain gambar dan pemilihan warna untuk menghindari rasa kebosanan siswa. Tujuan penelitian ini untuk mengetahui bagaimana proses pengembangan, kevalidan, kepraktisan, dan keefektifan ensiklopedia tata surya untuk digunakan olehsiswa kelas III sekolah dasar.

Ensiklopedia berbentuk scrapbook dapat melatih kemampuan motorik siswa dibandingkan dengan ensiklopedia yang tidak menggunakan model scrapbook. Scrapbook dapat meningkatkan kemampuan kognitif siswa yang diperoleh melalui aspek pemahaman serta regulasi siswa yang didapat dalam aspek pemantauan. ${ }^{6}$ Manfaat yang diharapkan dari ensiklopedia tata surya berbentuk scrapbook dengan pendekatan konsep inkuiri ini dapat melatih siswa untuk mengembangkan daya berpikirnya dan mengembangkan suatu konsep dalam kehidupan nyata secara mandiri.

Berdasarkan hal tersebut, guru akan memiliki sebuah inovasi bahan ajar yang baru dan unik karena dilengkapi dengan bentuk scrap book (sebuah kerajinan tangan berbahan kertas lipat dengan teknik gunting dan tempel) yang dapat melatih kemampuan motorik siswa dalam menggerakkan otot-otot kecil di tangannya.

\footnotetext{
${ }^{5}$ Nurhatmi Jules, Dkk. (2015). Pengembangan Ensiklopedia Digital Energi ListriBerbasis Contextual Teaching and Learning (CTL) ), Jurnal Ilmu Pendidikan, 4 (1): $1-6$.

${ }^{6}$ Alfiah, A. N., Putra, N. M. D., \& Subali, B. (2018). Media Scrapbook Sebagai Jurnal Refleksi Untuk Meningkatkan Kemampuan Kognitif Dan $\quad$ Regulasi Diri. 3(1), 57-67.
} 
Sehingga bahan ajar yang diberikan akan menarik siswa serta meningkatkan minat baca dalam menggali ilmu pengetahuan sehingga gerakan literasi di sekolah akan berjalan dengan baik.

\section{METODE PENELITIAN}

Penelitian berikut adalah penelitian pengembangan atau Research and Development (R\&D). Penelitian ini menggunakan model ADDIE. Model pengembangan terdiri dari empat tahapan yakni tahap analisis (Analyze), tahap perancangan (Design), tahap pengembangan (Development), tahap implementasi (Implementation). Tahap evaluasi (Evaluation) tidak dilakukan karena keterbatasan waktu penelitian.

Penelitian dilaksanakan pada tahun ajaran 2020/2021 semester genap. Subjek dalam penelitian yaitu siswa kelas III, bertempat di SDN Sukun 1 Malang sebanyak 10 orang siswa. Setelah semua data terkumpul maka akan dilakukan teknik analisis data. Metode pengolah data penelitian menggunakan metode analisis data kuantitatif dengan penilaian berupa skor oleh tim ahli serta calon pengguna.

Instrumen yang digunakan untuk mengukur kevalidan berbentuk lembar validasi angket yang diberikan kepada dosen ahli media, ahli materi, dan ahli bahasa sebagai pertimbangan terhadap penilaian dan masukan mengenai pengembangan ensiklopedia tata surya terutama untuk digunakan siswa kelas III sekolah dasar. Angket kepraktisan guru juga mencangkup tiga aspek penilaian diantaranya bahasa dan keterbacaan, organisasi penyajian dan isi. Sedangkan pada angket kepraktisan siswa memiliki beberapa aspek yang dinilai diantaranya motivasi, kemenarikan, kemudahan, dan kemanfaatan. Angket tersebut akan mengacu pada skala Likert dengan empat kriteria diantaranya kriteria 1) sangat tidak baik, 2) tidak baik, 3) baik, 4) sangat baik. Kegiatan revisi akan dilakukan apabila pengembangan ensiklopedia tata surya untuk siswa kelas III sekolah dasar melalui hasil dari data dinyatakan "tidak valid", sedangkan apabila pengembangan ensiklopedia tata surya untuk siswa kelas III sekolah dasar dinyatakan "valid" maka media tersebut disebut layak untuk digunakan dan dikembangkan. 
Uji validitas digunakan untuk mengukur kelayakan ensiklopedia tata surya yang diperoleh dari tiga validator diantaranya ahli media, materi, dan ahli bahasa melalui data kuantitatif. ${ }^{7}$

$$
\text { Presentase }(\%)=\frac{\text { skor yang diperoleh }}{\text { skor yang diharapkan }} \times 100 \%
$$

Untuk mengetahui kategori kevalidan ensiklopedia agar dapat digunakan adalah dengan menghitung rata-rata hasil presentase uji validasi oleh ahli media, ahli materi, dan ahli bahasa menggunakan konversi skor kevalidan. ${ }^{8}$

Tabel 1

Konversi Skor Kelayakan

\begin{tabular}{|c|c|}
\hline Presentase Pencapaian & Inteprestasi \\
\hline $76 \%-100 \%$ & Layak \\
\hline $56 \%-75 \%$ & Cukup Layak \\
\hline $40 \%-55 \%$ & Kurang Layak \\
\hline $0-39 \%$ & Tidak Layak \\
\hline
\end{tabular}

Untuk menilai kepraktisan ensiklopedia melalui tanggapan guru dan siswa maka rumus penghitungan sama dengan analisis kepraktisan. ${ }^{9}$

$$
\text { Presentase }(\%)=\frac{\text { skor } \text { yang diperoleh }}{\text { skor yang diharapkan }} \times 100 \%
$$

\footnotetext{
${ }^{7}$ Sugiyono. (2009). Metode Penelitian Pendidikan dan $R \quad \& D$. Bandung: Alfabeta.

${ }^{8}$ Arikunto, Suharsini. (2013). Prosedur Penelitian.

${ }^{9}$ Sugiyono. (2009). Metode Penelitian Pendidikan dan $R \quad \& D$. Bandung: Alfabeta.
}

Pendekatan Kuantitatif, Kualitatif,

Jakarta: Rineka Cipta.

Pendekatan Kuantitatif, Kualitatif,

Vol. 2, No. 2, Desember 2020 
Hasil skor yang diperoleh akan dikonversikan menjadi nilai kualitatif sesuai tabel 2 dan $2 .^{10}$

Tabel 2

Konversi Skor Kepraktisan Guru

\begin{tabular}{|c|c|}
\hline Presentase (\%) & Kriteria Kualitatif \\
\hline $80 \%-100 \%$ & Sangat Baik \\
\hline $66 \%-79 \%$ & Baik \\
\hline $56 \%-65 \%$ & Cukup Baik \\
\hline $40 \%-55 \%$ & Kurang Baik \\
\hline $30 \%-39 \%$ & Gagal \\
\hline
\end{tabular}

Tabel 3

Konversi Skor Kepraktisan Siswa

\begin{tabular}{|c|c|}
\hline Presentase (\%) & Kriteria Kualitatif \\
\hline $80 \%-100 \%$ & Sangat Baik \\
\hline $66 \%-79 \%$ & Baik \\
\hline $56 \%-65 \%$ & Cukup Baik \\
\hline $0 \%-55 \%$ & Kurang Baik \\
\hline
\end{tabular}

Data yang dipakai untuk mengukur tingkat keefektifan ensiklopedia tata surya untuk siswa kelas III sekolah dasar melalui data tes setelah siswa menggunakan media ensiklopedia dengan analisisis kuantitatif, yaitu menentukan rata-rata nilai tes dengan rumus $:^{11}$

$$
\text { Presentase }(\%)=\frac{\text { skor yang diperoleh }}{\text { skor yang diharapkan }} \times 100 \%
$$

Ensiklopedia Tata Surya Untuk Siswa Kelas III Sekolah Dasar dikatakan efektif jika nilai rata-rata belajar siswa secara keseluruhan mencapai nilai minimal $70 . .^{12}$

Tabel 4

Kriteria Keefektifan

\begin{tabular}{|c|c|}
\hline Skor Keefektifan & Tingkat Validitas \\
\hline $85-100$ & $\begin{array}{c}\text { Sangat efektif, tidak perlu } \\
\text { revisi }\end{array}$ \\
\hline $70-84$ & Efektif, tidak perlu revisi \\
\hline $50-69$ & Kurang efektif, perlu revisi \\
\hline $0-49$ & Tidak efektif, revisi total \\
\hline
\end{tabular}

\footnotetext{
${ }^{10}$ Arikunto, Suharsimi. (2009). Manajemen Penelitian. Jakarta: Rineka Cipta.

${ }^{11}$ Sugiyono. (2009). Metode Penelitian Pendidikan Pendekatan Kuantitatif, Kualitatif, dan $R \quad \& D$. Bandung: Alfabeta.

${ }^{12}$ Yamasari. (2010). Kriteria Keefektifan E- Evaluation Berbasis Aplikasi Hot Potatoes.
} 


\section{HASIL PENELITIAN DAN PEMBAHASAN}

Pengembangan ensiklopedia tata surya ini menggunakan model ADDIE. Dalam tahapan analisis kebutuhan, ditemukan bahwa di SDN Sukun 1 Malang belum memiliki ketersediaan buku seperti ensiklopedia tata surya berbasis inkuiri untuk siswa kelas III sekolah dasar. Berdasarkan hasil analisis kompetensi dasar ditemukan bahwa pengembangan ensiklopedia tata surya sesuai dengan Tema 8 Bumi dan Alam Semesta pada pembelajaran IPA dengan kompetensi dasar IPA.

Pada analisis karakteristik siswa ditemukan siswa yang pasif saat mengikuti kegiatan pembelajaran.Pada tahapan desain peneliti melakukan analisis pada buku yang sudah ada sebagai referensi untuk desain buku ensiklopedia, kemudian membuat kerangka desain yang dibuat dengan softwareaplikasi Corel Draw Xseperti pada hasil di bawah ini :

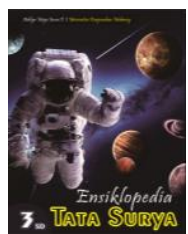

r.

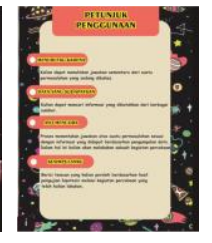

Gambar

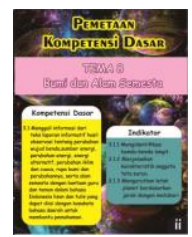

Gambar

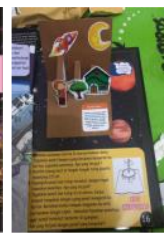

Gambar

Peneliti melakukan kegiatan perancangan instrument dan pembuatan produk yang akan dilanjutkan dengan kegiatan perbaikan melalui revisi produk untuk pencapaian tujuan pembelajaran. Dalam perancangan ensiklopedia dilakukan penambahan background dan ilustrasi yang berhubungan dengan tata surya. Selain itu, pada ensiklopedia, peneliti menambahkan langkah-langkah pendekatan inkuiri untuk memperdalam materi tata surya yang berhubungan dengan masalah dalam kehidupan sehari-hari dengan bentuk scrap book yang dapat menarik perhatian siswa dan melatih motorik siswa.

Ensiklopedia diimplementasikan kepada siswa kelas III sekolah dasar dengan jumlah sebanyak 10 siswa yang bertempat di SDN Sukun 1 Malang. Tujuan dari validasi oleh ahli media ialah mengetahui kelayakan ensiklopedia. Berdasarkan 
hasil yang didapat dari ahli media, bahwa ensiklopedia yang dikembangkan dikategorikan layak dengan presentase sebesar 92\%. Tujuan dari validasi oleh ahli materi ialah mengetahui kelayakan ensiklopedia. Berdasarkan hasil yang didapat dari ahli materi, bahwa ensiklopedia yang dikembangkan dikategorikan layak dengan presentase sebesar $96 \%$.

Validasi oleh ahli digunakan mengetahui kelayakan ensiklopedia. Hasil penilaian dari ahli bahasa, bahwa ensiklopedia yang dikembangkan dikategorikan layak dengan presentase sebesar 93\%. Kepraktisan ensiklopedia digunakan untuk mengetahui kepraktisan ensiklopedia. Berdasarkan penilian dari praktisi, ensiklopedia yang dikembangkan dikategorikan layak dengan presentase sebesar 80\%. Dalam uji kepraktisan ensiklopedia oleh siswa, bahwa ensiklopedia yang dikembangkan dikategorikan "sangat baik" dengan presentase sebesar 87\%.

Hasil penilaian keefektifan ensiklopedia yang dikembangkan dikategorikan “efektif” dengan presentase sebesar $81 \%$, hasil tersebut didapatkan melalui hasil tes soal pilihan ganda yang diberikan kepada 10 orang siswa dan dapat disimpulkan bahwa ensiklopedia tersebut tidak memerlukan revisi. Buku ensiklopedia layak untuk digunakan berdasarkan data dari ahli materi, ahli media dan bahasa serta mendapatkan respon yang positif. Hal ini sejalan dengan penelitian Nuraida yang menyatakan bahwa pengembangan ensiklopedi layak, praktis dan efektif untuk digunakan dalam pembelajaran. ${ }^{13}$ Pengembangan ensiklopedia tata surya berbasis pendekatan inkuiri untuk siswa kelas III sekolah dasar dinyatakan layak, praktis, efektif digunakan sebagai bahan ajar.

${ }^{13}$ Nuraida, dkk. (2017). Pengembangan Ensiklopedia Morfologi, Anatomi Dan Fisiologi Pada Tumbuhan Berkarakter Khusus Development, Jurnal Ilmu Pendidikan, 14, 503-507. 


\section{KESIMPULAN}

Berdasarkan hasil penilaian dari validator maka ensiklopedia tata surya untuk siswa kelas III sekolah dasar dinyatakan valid atau layak dengan persentase dari ahli media sebanyak 92\% dalam kategori layak, presentase dari ahli materi sebanyak 96\% dalam kategori layak, dan persentase dari ahli bahasa sebanyak 93\% dalam kategori layak. Ensiklopedia tata surya untuk kelas III sekolah dasar juga dinyatakan praktis berdasarkan hasil penilaian dari guru mendapat hasil $80 \%$ dalam kategori sangat baik dengan penilaian siswa mendapat presentase $87 \%$ dalam kategori sangat baik. Ensiklopedia tata surya untuk siswa kelas III sekolah dasar dinyatakan efektif untuk digunakan siswa dengan persentase sebesar $81 \%$ dengan kategori efektif dan tanpa melalui revisi. 


\section{DAFTAR PUSTAKA}

Alfiah, A. N., Putra, N. M. D., \& Subali, B. (2018). Media Scrapbook Sebagai Jurnal Refleksi Untuk Meningkatkan Kemampuan Kognitif Dan Regulasi Diri. 3(1), 57-67.

Arikunto, Suharsimi. (2009). Manajemen Penelitian. Jakarta: Rineka Cipta.

Arikunto, Suharsini. (2013). Prosedur Penelitian. Jakarta: Rineka Cipta.

Azizah, M., Sulianto, J., \& Cintang, N. (2018). Analisis Keterampilan Berpikir Kritis Siswa Sekolah Dasar pada Pembelajaran Matematika Kurikulum 2013. Jurnal Penelitian Pendidikan A $\& A, 35(1), 61-\quad 70$.

Nuraida, dkk. (2017). Pengembangan Ensiklopedia Morfologi, Anatomi Dan Fisiologi Pada Tumbuhan Berkarakter Khusus Development, Jurnal Ilmu Pendidikan, 14, 503-507.

Rohman Sayifur. (2017). Membangun Budaya Membaca Pada Anak Melalui Program Gerakan Literasi Sekolah. Jurnal Pendidikan Dan Pembelajaran Dasar, 4, $\quad$ 151-174.

Silvia Citra Linda \& Hadiyanto. (2019). Implementasi Kebijakan Gerakan Literasi Sekolah (GLS) Dalam Rangka Menumbuhkan Minat Baca Siswa Di ～Sekolah Dasar. Jurnal Ilmu Pendidikan, 3(2), 524-532.

Situmorang, M. (2013). Pengembangan Buku Ajar Kimia SMA melalui Inovasi Pembelajaran dan Integrasi Pendidikan Karakter untuk Meningkatkan Hasil Belajar Siswa. Semirata FMIPA Universitas Lampung, 1(1), 237-246.

Nurhatmi Jules, Dkk. (2015). Pengembangan Ensiklopedia Digital Energi Listrik Berbasis Contextual Teaching and Learning (CTL) ), Jurnal Ilmu Pendidikan, 4 (1): 1-6.

Sugiyono. (2009). Metode Penelitian Pendidikan Pendekatan Kualitatif, dan $R \quad \& D$. Bandung: Alfabeta.

Kuantitatif,

Suyono, Harsiati, T., \& Wulandari, I. S. (2017). Implementasi gerakan literasi sekolah pada pembelajaran tematik di sekolah dasar. Sekolah Dasar: Kajian Teori Dan Praktik Pendidikan, 116-123.

Yamasari. (2010). Kriteria Keefektifan E- Evaluation Berbasis Aplikasi Hot Potatoes. 